\title{
Acid-base Equilibria of 1-(2-pyridylazo)-2-naphthol in Neutral and Charged Micellar Media
}

\author{
ASHA MATHEW ${ }^{1}$, P. SHYAMALA ${ }^{2 *}$ and A. SATYANARAYANA ${ }^{2}$ \\ 1'Department of Chemistry, S.I.W.S. College, Wadala, Mumbai 400003, India. \\ 2Department of Physical and Nuclear Chemistry \& Chemical Oceanography, \\ Andhra University, Visakhapatnam 530004, India. \\ *Corresponding author E-mail: shyamalapulipaka06@gmail.com
}

http://dx.doi.org/10.13005/ojc/360323

(Received: May 10, 2020; Accepted: June 11, 2020)

\begin{abstract}
Acid-base equilibria of 1-(2-Pyridylazo)-2-naphthol (PAN) in neutral, cationic and anionic micellar media were investigated by potentiometric method using Calvin-Wilson titration technique. Best fit chemical models obtained using MINIQUAD-75 program showed the presence of both mono-protonated $\left(\mathrm{LH}_{2}^{2+}\right)$ and deprotonated ( $\left.\mathrm{L}^{-}\right)$species of PAN $(\mathrm{LH})$ in solution. The equilibrium constants $\beta_{011}$ and $\beta_{012}$ corresponding to the formation of $\mathrm{LH}$ and $\mathrm{LH}^{2+}$ species respectively from the most anionic form ( $\mathrm{L}^{-}$) of PAN at a temperature of $30.0 \pm 0.1^{\circ} \mathrm{C}$ and an ionic strength of $0.1 \mathrm{~mol}$. $\mathrm{dm}^{-3}$ are reported. Several interesting results emerged from the study of the affect of the neutral and charged micelles on the equilibria are explained on the basis of the pseudo phase ionic exchange model, dielectric constant, polarity, hydrophilic and hydrophobic properties of micelles. Species distribution diagrams are generated using HYSS program.
\end{abstract}

Keywords: Chemical Speciation, PAN, Micelles, Formation constants, CTAB, SDS, TX-100.

\section{INTRODUCTION}

1-(2-Pyridylazo)-2-naphthol (PAN) belongs to a group of compounds known as $\mathrm{N}$-heterocyclic azo reagents that have great importance in the determination of metal ions. These reagents are outstanding in the photometric sensitivity of their metal complexes, because of the presence of heterocyclic nitrogen, the azo group and usually a phenolic hydroxyl group within a single molecule. Low solubility or insolubility of these chromogenic regents and/or their metal complexes in water, made it mandatory to use carcinogenic organic solvents.
However, in recent years ${ }^{1-21}$, these problems are adequately solved by using aqueous solutions of surfactants as Green solvents with an added benefit of improving the sensitivity of the determinations.

The indicator $\pm \mathrm{H}^{+}$eqillibria ${ }^{22}$, their colour and absorption properties are influenced by micellar systems. Hartley ${ }^{23}$ gave a simple sign rule based on the valence charge of the indicator and electrostatic interactions with charged surfactant in order to explain some micellar effects on indicator equilibria. If the indicator is neutral in one form, then the equilibrium will be displaced to the basic side by

This is an Open Access article licensed under a Creative Commons license: Attribution 4.0 International (CC- BY). Published by Oriental Scientific Publishing Company @ 2018

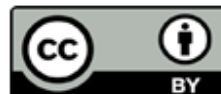


cationic and to the acidic side by anionic micellar systems. It was also reported that anionic micelles do not influence indicator equilibria of the type, $\mathrm{In}^{-} \leftrightharpoons \mathrm{In}^{2-}$ and cationic surfactants do not influence equilibria of the type, $\mathrm{In}^{+} \leftrightharpoons \mathrm{In}^{2+}$ while micellar systems of the opposite charge alter these equilibria. If the indicator in the equilibrium is of opposite sign to that of the micelle, then the direction of equlibrium may also depend on other specific factors such as hydrophobic and micro-solvent interactions ${ }^{22-25}$.

$\mathrm{pK}_{\mathrm{a}}$ and colour changes of the chelometric indicators depend on the solubilization and association of the indicator with neighbouring surfactant molecules in the micellar systems. Some anionic indicators of the triphenyl methane family are solubilized at the positively charged cationic micellar surface by electrostatic and hydrophobic interactions. Their protolytic dissociations are promoted due to favourable positive charge-dipole interactions ${ }^{26,27}$.

Cationic micelles have been reported to lower the $\mathrm{pK}_{\mathrm{a}}$ values of chelometric indicators ${ }^{26}$. The positive charge-dipole interactions which lower the $\mathrm{pK}_{\mathrm{a}}$ are reduced by increased ionic strength ${ }^{28}$ or decreased dielectric constants of the solution ${ }^{29}$. The higher $\mathrm{pK}_{\mathrm{a}}$ values may be attributed to the low dielectric constant of the medium compared to water apart from the other electrostatic effects.

Depending on the $\mathrm{pH}$ of the solution PAN (LH) exists in three forms. Acid solutions $(\mathrm{pH}<2)$ contain the yellow-green protonated $\mathrm{LH}_{2}{ }^{+}$ion which is water soluble. Between $\mathrm{pH} 3$ and 11, PAN exists in the neutral $\mathrm{LH}$ form which is soluble in organic solvents to give a yellow colour solution In aqueous solutions it is turbid). In alkaline solutions where $\mathrm{pH}>11$ PAN exists in the red $\mathrm{L}^{-}$anion which is water soluble Figure 1.

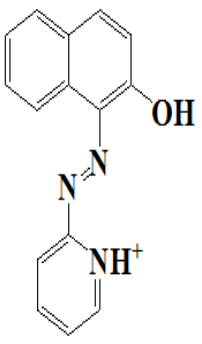

$\left(\mathrm{LH}_{2}^{+}\right)$

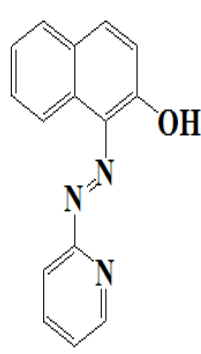

(LH)

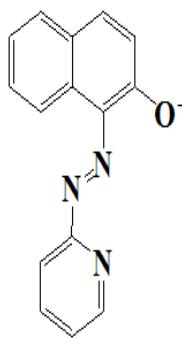

$\left(\mathrm{L}^{-}\right)$
Fig. 1. protonated and deprotonated species of pan (LH)
Thus, the acid-basic equilibria of PAN may contain $\mathrm{LH}_{2}{ }^{2+}$, $\mathrm{LH}$ and $\mathrm{L}^{-}$type of species in solution. In literature there is only one report on the protonation constants of PAN in surfactant media ${ }^{30}$ (Polyoxyethylene nonylphenols). All the others ${ }^{31-36}$ are in aqueous-organic solvent mixtures. Therefore, it is worthwhile to study the effect of the special properties of neutral, cationic and anionic micellar systems on the acid-base equilibria of PAN. The surfactants used in the present work along with their CMCs are shown in Table 1. The concentrations of surfactants maintained in this study are far above the respective $\mathrm{CMC}$ values.

Table 1: CMC values of the surfactants used in the study

\begin{tabular}{|c|c|c|c|}
\hline Type & Name of the surfactant & $\begin{array}{c}\text { CMC in } \\
\text { water }(\mathrm{mM})\end{array}$ & Reference \\
\hline \multirow[t]{2}{*}{ Cationic } & CTAB & & \\
\hline & $\begin{array}{l}\text { Cetyltrimethyl- } \\
\text { ammonium } \\
\text { bromide }\end{array}$ & 0.9 & 37,38 \\
\hline \multirow[t]{2}{*}{ Anionic } & SDS & & \\
\hline & $\begin{array}{l}\text { Sodium dodecylsulfate } \\
\text { (sodium laurylsulfate) }\end{array}$ & 8.1 & 39,40 \\
\hline \multirow[t]{3}{*}{ Non-ionic } & Triton $\mathrm{X}-100$ & & \\
\hline & Polyoxyethylene (9.5) & 0.22 to 0.24 & 41,42 \\
\hline & -t-octylphenol & & \\
\hline
\end{tabular}

\section{MATERIALS AND METHOD}

A $0.06 \mathrm{~mol} \mathrm{dm}^{-3}$ stock solution of 1-(2Pyridylazo)-2-Naphthol (Reidal) was prepared by dissolving an appropriate amount in respective aqueous-surfactant solution of known concentration. The solutions were then standardized using the methods in literature ${ }^{43}$. A $0.2 \mathrm{~mol} \mathrm{dm}^{-3}$ solution of sodium hydroxide (Merck) was prepared by first dissolving it in double distilled water and standardizing against potassium hydrogen phthalate (Merck). The solution was Gran-titrated to check the presence of any carbonates 44,45 and stored in a Pyrex vessel under nitrogen atmosphere. A 0.2 mol dm-3 solution of hydrochloric acid was prepared from analytical grade sample (Merck EMSURE®.) by successive dilutions and standardized against sodium hydroxide.

A Control Dynamics $\mathrm{pH}$-meter model APX $175 \mathrm{E} / \mathrm{C}$ in conjunction with a combination electrode (0-14 $\mathrm{pH}$ range) was used for $\mathrm{pH}$ measurements. The electrode system was calibrated in terms of hydrogen ion concentration in aqueous solution as per the IUPAC46 recommendations. The temperature 
of the solution was maintained by passing water from a thermostat through the annular space between the walls of the titration vessel. Purified nitrogen gas was passed through the experimental solution both before and during the titration to expel carbon dioxide.

\section{Data Acquisition and Analysis}

Calvin-Wilson titration technique ${ }^{47,48}$ was used for the study of acid-base equilibria of PAN in aqueous-surfactant media. Required volumes of hydrochloric acid (to give an overall concentration of 0.02-0.05 mol. $\mathrm{dm}^{-3}$ ), sodium chloride (ionic strength was maintained at $0.1 \mathrm{~mol}^{-\mathrm{dm}^{-3}}$ ), solution of surfactant and water in the presence and absence of PAN in a total volume of $50 \mathrm{~cm}^{3}$ was titrated with 0.2 mole $\mathrm{dm}^{-3}$ sodium hydroxide. The overall surfactant concentration in each titration was maintained at $0.02 \mathrm{M}$. Freshly prepared solution of PAN in $0.06 \mathrm{M}$ surfactant was used in all the titrations and the overall concentration of PAN was maintained between 0.004 to $0.01 \mathrm{~mol} . \mathrm{dm}^{-3}$ in different experiments. The $\mathrm{pH}$ correction factor and ionic product of water were calculated by Gran method ${ }^{44,45}$.

\section{RESULTS AND DISCUSSION}

Preliminary experiments revealed that, an addition of a drop of 0.1 mole $\mathrm{dm}^{-3}$ alkali suddenly raised the $\mathrm{pH}$ of PAN solutions to about $\sim 9.0$. This indicates that PAN does not possess any dissociable protons in the $\mathrm{pH}$ region below 9.0. The $\mathrm{pH}$ metric titration data for PAN in CTAB, SDS and Triton X-100 are shown graphically in Fig. 2a, 3a and $4 a$ respectively. Curve- 1 represents titration of hydrochloric acid in the absence of PAN, while curve- 2 represents the titration of acid + PAN with sodium hydroxide. The titration curves of PAN in all the surfactant media (curve 2 in Fig. 2a, 3a and 4a) are above that of free acid below a $\mathrm{pH}$ of $\sim 4.5$. This difference between the free acid and ligand curves in the lower $\mathrm{pH}$ region indicates the presence of proton associable centres in the PAN molecule. In the case of SDS this difference is more when compared to CTAB and Triton X-100 media. This indicates higher values of proton association constants for PAN in SDS compared to other surfactants.

On the basic side, i.e. above $\mathrm{pH} \sim 9.0$, there is a significant lowering of the PAN titration curves relative to free acid indicating deprotonation of the $-\mathrm{OH}$ group. This difference is more for PAN in CTAB medium compared to SDS and Triton X-100 media. In between these two $\mathrm{pH}$ regions free acid and acid +PAN curves coincide indicating the absence of proton-ligand equilibria.
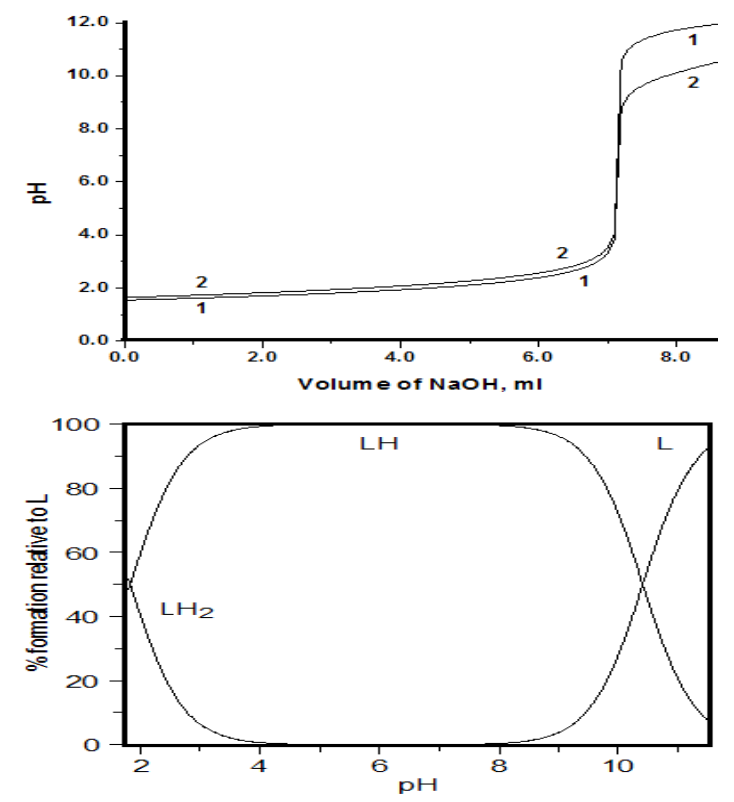

a. 1. Titration curve of free mineral acid b. Species distribution diagram

2. Titration curve for acid + pan $[P a n]=0.0100 \mathrm{~mol} \mathrm{dm}^{-3}[\mathrm{hcl}]$

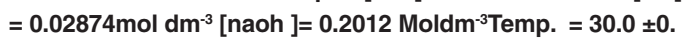
$1^{0} \mathrm{C}$ total volume $=50.0 \mathrm{~cm}^{3} \mathrm{i}=0.1 \mathrm{Mol} \mathrm{dm}^{-3} \mathrm{nacl}$

Fig. 2. Proton-ligand system of pan in ctab medium
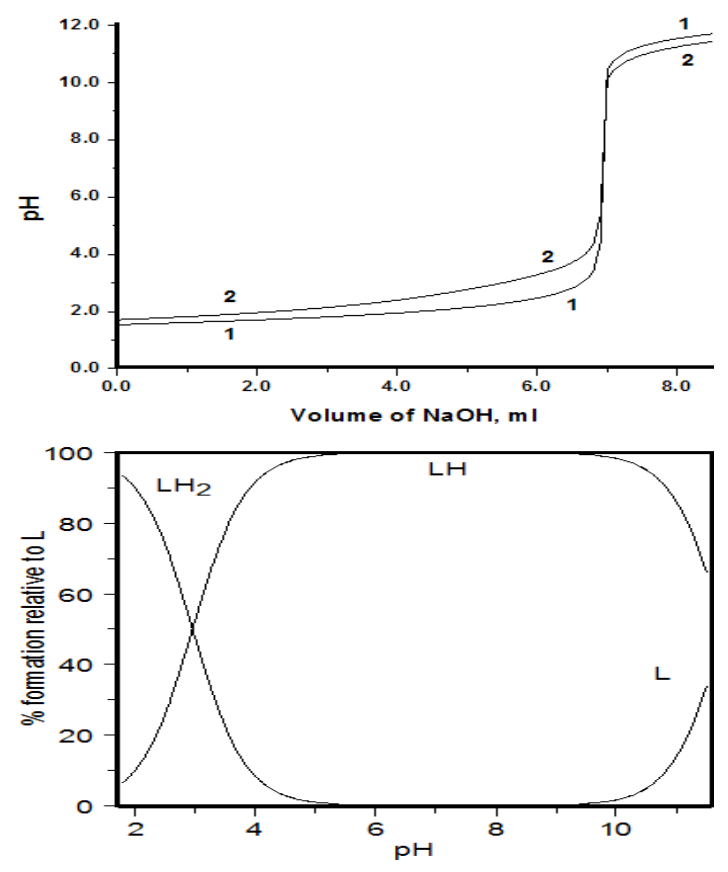

a.1. Titration curve of free mineral acid b. Species distribution diagram 2. Titration curve for acid + pan $[P a n]=0.0100 \mathrm{~mol} \mathrm{dm}^{-3}[\mathrm{hcl}]=$ $0.02886 \mathrm{~mol} \mathrm{dm}^{-3}[\mathrm{naoh}]=0.2088 \mathrm{Moldm}^{-3} \mathrm{Temp}=30.0 \pm 0.1^{\circ} \mathrm{C}$ total volume $=50.0 \mathrm{~cm}^{3} \mathrm{i}=0.1 \mathrm{Mol} \mathrm{dm}^{-3} \mathrm{nacl}$

Fig. 3. Proton-ligand system of pan in sds medium 

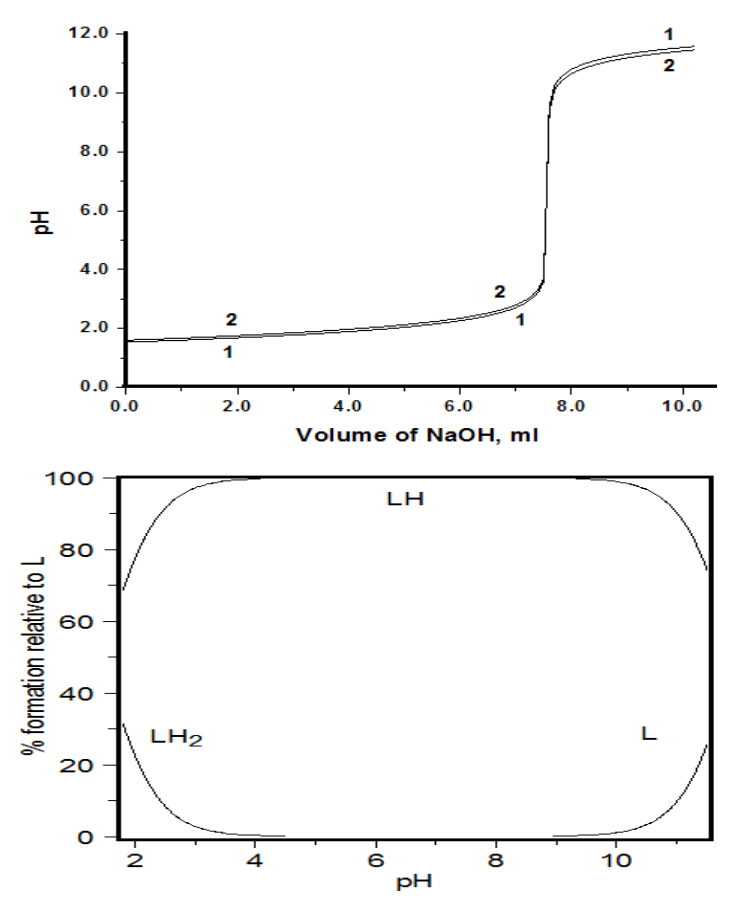

a. 1. Titration curve of free mineral acid b. Species distribution diagram

2. Titration curve for acid + PAN $[P A N]=0.0100 \mathrm{moldm}^{-3}[\mathrm{HCl}]=$ $0.02900 \mathrm{moldm}^{-3}[\mathrm{NaOH}]=0.1914 \mathrm{moldm}^{-3} \mathrm{Temp} .=30.0 \pm 0.1^{\circ} \mathrm{C}$ Total volume $=50.0 \mathrm{~cm}^{3} \mathrm{I}=0.1 \mathrm{moldm}^{-3} \mathrm{NaCl}$

Fig. 4. Proton-ligand system of pan in triton $x-100$ medium

The acquired data were subjected to analysis by MINIQUAD-75 program ${ }^{49}$. The best-fit models thus obtained Tables 2 contain two formation constants $\beta_{011}$ and $\beta 0_{12}$ corresponding to the formation of $\mathrm{LH}$ and $\mathrm{LH}_{2}{ }^{+}$species respectively from the most anionic form of PAN $\left(\mathrm{L}^{-}\right)$as shown in Figure 5.<smiles>[O-]c1ccc2ccccc2c1N=Nc1ccccn1</smiles>

(L)<smiles>[O-]c1ccc2ccccc2c1N=Nc1ccccn1</smiles>

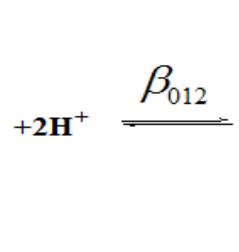

(L)

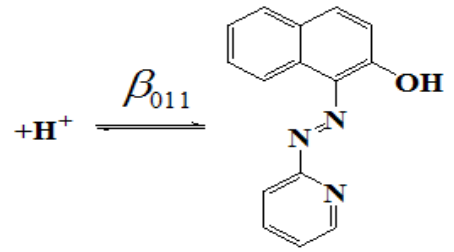

(LH)

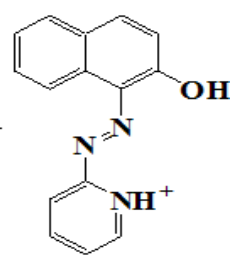

$\left(\mathrm{LH}_{2}{ }^{+}\right)$
Fig. 5. Acid-base equilibria of PAN
Table 2: Best fit chemical models for acid-base equilibria of PAN in $0.02 \mathrm{M}$ surfactant medium. (Temp. $=30.0 \pm 0.1^{\circ} \mathrm{C}$ and ionic strength, $\mathrm{I}=0.1 \mathrm{~mol}$ $\mathrm{dm}^{-3}(\mathrm{NaCl})$

\begin{tabular}{|c|c|c|c|c|c|}
\hline Surfactant & $\begin{array}{c}\text { Species } \\
\text { MIh }\end{array}$ & $\begin{array}{l}\log \beta_{\text {olh }} \\
\text { (SD) }\end{array}$ & $\begin{array}{l}\text { Number of } \\
\text { experimental } \\
\text { points } \\
\text { analysed }\end{array}$ & $\begin{array}{l}\text { Sum of the } \\
\text { squares of } \\
\text { residuals, } U\end{array}$ & $\chi^{2}$ \\
\hline & 11 & $10.41(4)$ & & & \\
\hline \multirow[t]{2}{*}{ CTAB } & 12 & $12.24(5)$ & 105 & $9.034 \times 10^{-8}$ & 4.02 \\
\hline & 11 & $11.79(5)$ & & & \\
\hline \multirow[t]{2}{*}{ SDS } & 12 & $14.75(5)$ & 81 & $6.792 \times 10^{-8}$ & 14.79 \\
\hline & 11 & $11.96(5)$ & & & \\
\hline $\begin{array}{l}\text { Triton } \\
\mathrm{X}-100\end{array}$ & 12 & $13.42(6)$ & 130 & $6.004 \times 10^{-8}$ & 12.06 \\
\hline
\end{tabular}

$\mathrm{SD}=$ Standard Deviation in the least significant digit

The species distribution diagram for acidbase equilibria of PAN in CTAB micellar medium (Fig.2b) indicates that the $\mathrm{LH}_{2}{ }^{+}$form of PAN exists only below a pH of 4.5. The formation of $\mathrm{LH}_{2}{ }^{+}$species (Fig. 5) may be due to the protonation of the ligand at the pyridine nitrogen atom. The extent of its formation is $52 \%$ at $1.8 \mathrm{pH}$. With the increase in $\mathrm{pH}$ this species deprotonates and above a $\mathrm{pH}$ of 4.5 and up to $8.5 \mathrm{pH}$, PAN totally exists in neutral $\mathrm{LH}$ form. Above this $\mathrm{pH}$, deprotonation of $-\mathrm{OH}$ group takes place leading to the formation of L-species. The extent of formation of $\mathrm{L}$ - reaches $93 \%$, in the $\mathrm{pH}$ region $(\sim 11.5 \mathrm{pH})$ of study. In SDS micellar media, $\mathrm{LH}_{2}{ }^{+}$form of PAN seems to be dominating and represents nearly $94 \%$ of the ligand (Fig. $3 \mathrm{~b}$ ) at a $\mathrm{pH}$ of 1.8. It deprotonates totally below $5.5 \mathrm{pH}$ and the entire ligand is in the neutral $\mathrm{LH}$ form between 5.5 and $9.5 \mathrm{pH}$. Further increase in $\mathrm{pH}$ deprotonates the-OH group of PAN. Formation of the anionic form of PAN reaches a maximum of $30 \%$ at $11.4 \mathrm{pH}$. In the presence of Triton X-100 micelles the formation of $\mathrm{LH}_{2}{ }^{+}$species (Fig. $4 b$ ) is only $30 \%$ at 1.8 $\mathrm{pH}$. In the $\mathrm{pH}$ region between 4.0 and $9.5 \mathrm{pH}, \mathrm{PAN}$ exists only in neutral LH form. The formation of anionic form of PAN is only $26 \%$ in the $\mathrm{pH}$ region of study.

The insolubility of PAN in water and its solubility in micellar solutions, indicate, at first glance, the probability of its solubilization in the hydrophobic micellar core ${ }^{50}$. But NMR studies by K. N. Ganesh et al., ${ }^{51}$ on aromatic optical probes showed that the polar functional groups and /or aromatic rings of the guest molecules reside on average within the interfacial head-group region of the host charged micelles. Suratkar et al., ${ }^{52}$ by their proton NMR studies on the solubilization of organic molecules 
in SDS micelles, confirmed that aromatic molecules that possess phenolic - $\mathrm{OH}$ group reside at the hydrophilic/hydrophobic boundary of micelle-water interface. Therefore, the most probable position of the PAN molecule may be in the hydrophilic/ hydrophobic boundary of the interface. Micellar effect on acid-base equilibria of PAN therefore, may be understood in the light of both characteristic electrostatic and micro environmental factors of the respective surfactants.

Equilibria for the step-wise protonation of PAN from its most anionic form $L^{-}$and the corresponding step-wise formation constants obtained for all the surfactant media investigated are shown in Table 3. The values reported are with reference to a fixed concentration of surfactant above the critical micellar concentration values. Several interesting results emerged from these studies. A reasonable interpretation of the results is as follows. In the case of first protonation of the most anionic form of PAN, $\left(\mathrm{L}^{-}+\mathrm{H}+\leftrightharpoons \mathrm{LH}\right)$, the corresponding formation constants for SDS and Triton X-100 media are higher compared to that of CTAB. It means anionic and non-ionic surfactants strongly increase the proton association to $\mathrm{L}^{-}$form of PAN, whereas the cationic surfactant retards the association. These effects are in agreement with the "Pseudo phase ion-exchange model" of micelles.

Table 3: Step-wise protonation constants of the most anionic form of PAN in aqueous-surfactant media

S.No. Protonation equilibria of PAN Step-wise protonation constants $\mathrm{CTAB}^{\text {SDS }}$ Triton X-100

In CTAB, the $\log \mathrm{K}_{1}$ value for proton association is low because PAN $\left(\mathrm{L}^{-}\right)$in $\mathrm{R}-\mathrm{O}$ - form is stabilized by electrostatic attraction by cationic head groups of the micelle. This facilitates the dissociation of $\mathrm{R}-\mathrm{OH}$ to $\mathrm{R}-\mathrm{O}$ - which decreasing the protonation constant. The repulsive interaction of negative charge on the dissociated particle, R-O of PAN and anionic head groups of SDS micelles strengthen the $-\mathrm{O}-\mathrm{H}$ bond. Therefore, the negative charge of SDS micellar surface is favourable for the formation of neutral $\mathrm{LH}$ form of PAN from $L$ : In the case of Triton $X-100$ which is a non-ionic surfactant, as there is no electrostatic effect and only the polarity effect has a major role. The dielectric constant of the micellar phase is lower than that of water, and when PAN is solubilized in this phase the association equilibrium is moved to the right which increasing proton association constant, $\log \mathrm{K}_{1}$. It is also possible that the presence of several hydrophilic polyethylene oxide chains increase the number of hydrogen bonds, and therefore dissociation is enhanced. But the observed results show that the polarity factors outweigh the hydrogen bonding factor causing an overall decrease in dissociation. The neutral form of PAN (LH) is hydrophobic and is preferably drawn towards the hydrophobic core of the micelles, decreasing the possibility of ionization. Further protonation of PAN i.e protonation of $\mathrm{LH}$ form leading to the formation of $\mathrm{LH}_{2}{ }^{+}$is also affected by the micellar media as reflected in the corresponding $\log \mathrm{K}_{2}$ values shown in Table 3. The relatively higher value of $\log \mathrm{K}_{2}$ (2.96) for SDS micelles indicates that $\mathrm{LH}_{2}{ }^{+}$species of PAN is stabilized through the formation of ion-pair with anionic sulphate head groups of SDS micelles. This indicates that the protonated heterocyclic nitrogen of PAN has a specific molecular interaction with the anionic sulphate head groups within the interfacial microenvironment. It can also be explained on the basis of a charge induced shift in surface $\mathrm{pH}$ of the micelles ${ }^{53-55}$. The $\mathrm{pH}$ of the surface of the SDS micelles is lowered due to binding of protons as counter ions by ion exchange equilibria. The lowering 
of $\mathrm{pH}$ promotes the formation of protonated species increasing the corresponding formation constant.

The values of $\log \mathrm{K}_{2}$ were found to be relatively lower in CTAB and Triton X-100 micellar media. In the case of CTAB this is expected as the protonated cationic form is less favourable in cationic micellar media of CTAB due to charge repulsion. Further, the charge induced shift in local surface $\mathrm{pH}$, which is increased in the case of cationic surfactants due to repulsion of protons and binding of hydroxide ions $^{53-55}$, decreases the protonation constant. This increase in surface $\mathrm{pH}$ works against the protonation of the species. Therefore, the equilibrium (2) in Table 3 shifts towards left resulting in a decrease of the formation constant. In neutral Triton X-100 micellar medium, in the absence of surface charge effects, the hydrophobic neutral form of PAN (LH) is preferred again lowering the formation constant of further protonation. In conclusion, micellar media induces significant shifts in protonation equilibria of PAN that can beexplained in terms of hydrophobicity and electrostatic interactions.

\section{CONCLUSION}

The acid-basic equilibria of PAN contains
$\mathrm{LH}_{2}{ }^{2+}$, $\mathrm{LH}$ and $\mathrm{L}^{-}$type of species in solution and therefore two formation constants $\left(\beta_{011}\right.$ and $\left.\beta_{012}\right)$. In the case of first protonation of the most anionic form of PAN, $\left(\mathrm{L}^{-}+\mathrm{H}+\leftrightharpoons \mathrm{LH}\right)$, the corresponding formation constants $\left(\log \mathrm{K}_{1}\right)$ for SDS and Triton $\mathrm{X}-100$ media are higher compared to that of CTAB which can be explained on the basis of electrostatic attraction between the cationic surfactant and $\mathrm{L}^{-}$form retards the association. The anionic and non-ionic surfactants strongly enhance the proton association to PAN. The relatively higher value of $\log \mathrm{K}_{2}$ for SDS micelles indicates that $\mathrm{LH}_{2}{ }^{+}$species of PAN is stabilized through the formation of ion-pair with anionic sulphate head groups of SDS micelles. In the case of $C T A B$, the protonated cationic form is less favourable in cationic micellar media of CTAB due to charge repulsion. The charge induced shift in local surface $\mathrm{pH}$, which is increased in the case of cationic surfactants decreases the protonation constant.

\section{ACKNOWLEDGEMENT}

PS thanks DST, New Delhi, India for financial support under the project SB/S1/IC-35/2013.

\section{Conflicts of Interest}

The authors declare no conflict of interest.

\section{REFERENCES}

1. Mohammad Asaduddin Laskar.; Sana Siddiqui and Aminul Islam.; Critical Reviews in Analytical Chemistry., 2016, 46(5), 413-423.

2. Asha Mathew.; Krishna Kumar. A.V., Shyamala. P., Satyanarayana. A. \& Rao. I.M., Indian Journal of Chemical Technology., 2012, 19, 331-336.

3. Asha Mathew, Shyamala. P., Satyanarayana. A.; Rao. I.M.; Journal of Indian chemical society., 2011, 88, 995-1000.

4. Islam. A.; Laskar M. A.; and Ahmad A.; J. Chem. Eng. Data., 2010, 55, 5553-5561.

5. Ghasem Karim-Nezhad, Lotfali Saghatforoush and Sohrab Ershad, Asian Journal of Chemistry., 2009, 21(4), 2565-2572.

6. Mufazzal Saeed Md., Separation Science and Technology., 2008, 43(4), 923-943.

7. Nezhad G.K.; Saghatforoush L.; Ershad S.; Bahrami K.; Chin. J. Chem., 2008, 26, 952-956.

8. Thanasarakhan W.; Liawruangrath S.; Wangkarn S.;Liawruangrath B.; Talanta., 2007, 71, 1849-1855.
9. Yanovska E.S.; Tertykh V.A.; Kichkiruk O.Yu.;Dadashev A.D.; Adsorption Science \& Technology., 2007, 25, 81-87.

10. Arvand M.; Abolghasemi S.; Zanjanchi M. A.; J. Anal chem., 2007, 62(4), 342-347.

11. Rod A. R.; Borhani S; Shemirani F; Eur. Food. Res. Tech., 2006, 223, 649-653.

12. Zarei K.; Atabati M.; and. Malekshabani Z; Analitica Chemica Acta., 2006, 556, 247-254.

13. Abbas Afkhami.;Morteza Bahra.; Microchim Acta., 2006, 155, 403-408.

14. Habibollah E.; Ali Ghanbari S.; Arab C. M; Turk J Chem., 2006, 30, 49-63.

15. Shar G.A.; Soomro G.A.; J. Chem. Soc. Pak., 2006, 28(1), 62-67.

16. Arab M.; Chamjangali, Bagherian G.;Azizi G., Spectrochemica Acta Part A., 2005, 62, 189-196.

17. Abbas Afkhani.; Morteza Bahram; Spectrochemica Acta Part A., 2004, 60, 181-186. 
18. Habeballah E.; Eskandari; Bull. Kor. Chem. Soc., 2004, 25, 1137-1142

19. Habeballah E.; Yousef Kamal; Analytical Sciences., 2004, 20, 1095-1098.

20. Shemirani E.; Abkenar Sh. D.; J. Anal. Chemistry., 2004, 59, 327-330.

21. Habeballah E.; Ali G.; Saghseloo; Analytical Sciences., 2004, 19, 1513-1518.

22. Fendler H.; Fendler E.; J.," Catalysis in micellar and Macromolecular systems", Academic Press., 1975.

23. Hartley G. S.; Trans. Faraday Soc., 1934, 30, 444.

24. Mukerjee P.; Banerjee K.; J. Phys, Chem., 1964, 68, 35.

25. Minch M. J.; Giaccio M.; Wolff R.; J. Amer. Chem. Soc., 1975, 97, 3766.

26. Kahara H.; Ishibashi N.; Masuzaki T.; Japan Anal., 1970, 19, 467.

27. Kahara H; Kitakyushu Kogyo Koto Semmon Gakko Kenkyu Hokoku., 1975, 9, 15.

28. Vekhande C. R.; Munshi K. N.; J. Indian Chem. Soc., 1973, 50, 385.

29. Kivillov A. I.; Makarenko O. P.; Poluektov N. S.; Lauer R. S.; Shaulina L. P.; Zh. Anal. Khim.,1973, 28, 1618.

30. Medina Escriche J.; Llobat Estelle M.; Bosch F; Reig. Talanta., 1983, 30(12), 915-918.

31. Sarin R.; Munshi K.N.; J.Ind.Chem.Soc., 1978, 55(5), 512-513.

32. Nakagawa G.; Wada H.; Nippon Kagaku Zasshi., 1963, 84, 639-641, CODEN: NPKZAZ; ISSN: 0369-5387.

33. Corsini A.; Mailing Yih I.; Fernando Q. Freiser H.; Anal. Chem., 1962, 34(9), 1090-1093.

34. Shibata S.; "Chelates in Analytical Chemistry"; Marcel Dekker, Inc., 1972, 4, 101-108.

35. Pease Burton F.; Williams Max B., Anal. Chem., 1959, 31, 1044-1047.

36. Bishop E., Ed.; "Indicators"; Pergamon Press: Oxford, England, 1972, 320, and also references quoted therein.
37. Neugebauer J.M.; Meth. Enzymol., 1990, 182, 239-253.

38. Harris E. L. V.; Angal S.; eds, "Protein Purification Applications: A Practical Approach", IRL Press at Oxford University Press, NY., 1990, 71.

39. Baumuller W.; Hoffmann H.; Ulbrich W.; Tondre C.; Zana R.; J. Colloid Interface Sci., 1978, 64, 418-437.

40. Domínguez A.; Fernández A.; González N.; Iglesias E. Montenegro L.; Journal of Chemical Education., 1997, 74(10), 1227.

41. Friberg S.E.; Rong G.; Ward A.J.I., J. Phys. Chem., 1988, 92, 7247.

42. Tiller G.E.; Anal. Biochem., 1984, 141, 262-266.

43. Pease B.F.; Williams M.B.; Anal. Hem., 1959, 31, 1044-1047.

44. Gran G.; Analyst., 1952, 77, 661.

45. Gran G.; Acta Chem. Scand., 1950, 4, 559.

46. Braibanti A.; Ostacoli G.; Paoletlti P.; Pettit L. D.; Sammartano S., Pure \& Appl. Chem., 1987, 59(12), 1721-1728.

47. Irving H. M; Rossotti H. S.; J. Chem. Soc., 1953, 3397-3405.

48. Irving H. M. Rossotti H. S.; J. Chem. Soc., 1954, 2904-2910.

49. Gans P.; Sabatini A.; Vacca A., Inorg. Chim. Acta., 1976, 18, 237-239.

50. Furton K. G.; Norelus A.; J.Chem.Ed., 1984, 70, 254-257.

51. Ganesh K. N.; Mitra P.; Balasubramanian D.; J. Phys. Chem., 1982, 86, 4291-4293 and references there in.

52. Suratkar V.V.; Mahapatra S.; J Colloid Interface Sci., 2000, 225(1), 32-38.

53. Quinaand F.H.; Chaimovich H.; J. Phys. Chem., 1982, 83, 1844-1850.

54. Bunton C.A.; Romstedand L.S.; Sepulveda L., J. Phys. Chem., 1980, 84, 2611-2618.

55. Romsted L.S.; in "Micellization, Solubilization, and Microemulsions", ed. by K.L. Mittal, 1977, 2, 509-530, Plenum Press, New York. 